\title{
Reality shows e voyeurismo: um estudo sobre os vícios da pós-modernidade*
}

\author{
Nancy Greca de Oliveira Carneiro \\ Andressa de Barros Cordeiro \\ Denise dos Santos Campos
}

\begin{abstract}
Do moderno ao pós-moderno novas formas de estabelecer relação com o outro advêm e, nesse processo, a imagem enquanto texto vai ocupando o seu lugar no discurso, falado ou escrito. $O$ trabalho em questão visa estabelecer algumas reflexões acerca do voyeurismo, tal como apresentado por Freud na perspectiva psicanalítica clássica, enquanto um traço de singularidade na construção da sexualidade do sujeito, daquele decorrente do impacto do visual na construção da subjetividade do homem na pós-modernidade, que se apresenta na forma dos reality shows (shows da vida) televisivos da atualidade. Dar destaque a esses deslocamentos e suas implicações no desejo leva-nos a estabelecer as novas formas de mal-estar no mundo contemporâneo.
\end{abstract}

Palavras-chave: Voyeurismo, desejo, reality shows, psicanálise, pós-modernidade

* Este texto foi originalmente produzido na disciplina do $4^{\circ}$ ano do Curso de Psicologia da PUC-PR, Teorias e Técnicas Psicoterápicas, pelas alunas Andressa de Barros Cordeiro e Denise dos Santos Campos, revisado e transformado em artigo pela professora Nancy Greca de Oliveira Carneiro. 


\section{Introdução}

Neste momento, em que a sociedade se dinamiza, globaliza e cresce, como um mar de pessoas que se vêem ao mesmo tempo cercadas por outros indivíduos e profundamente solitárias, é cada vez mais freqüente, na frenética busca por audiência, a produção de programas televisivos que utilizam como tema principal pessoas comuns em circunstâncias reais da vida cotidiana, observadas, ao vivo, por milhões de espectadores.

Esses programas, conhecidos por reality shows (shows da vida), puderam ser criados em decorrência da fantástica evolução tecnológica do século XX e da criação da Internet em suas últimas décadas. Segundo o site http://bb.sapo.pt/:

... estes [evolução tecnológica e Internet] são os princípios que permitiram a criação de programas baseados em experiências reais como o Big Brother, que está agora a ser transmitido na TV. As origens do "Big Brother" prendem-se com a própria história da Internet e com a investigação científica. Em 1991 surge o projeto Biosfera II, no qual um grupo de cientistas aceita viver numa casa isolada, dependendo apenas dos seus meios para a sobrevivência.

A Internet foi se desenvolvendo e permitindo a circulação de um número cada vez maior de imagens provenientes de toda parte do planeta. Ainda segundo o mesmo site, "Jennifer Ringley foi a pioneira desta nova moda. Colocou diversas câmaras em sua casa e começou a transmitir a sua vida via Internet. Outras experiências do mesmo gênero surgiram, e a aceitação foi bastante grande". 
A partir daí começaram a surgir filmes de altíssima audiência, baseados em observação da vida alheia, como Truman Show. ${ }^{1}$ No decorrer do processo, o surgimento de outros filmes experimentais relatando experiências reais ou em que os atores experimentavam sensações reais, como A Bruxa de Blair, ${ }^{2}$ propiciaram a passagem desse formato realista para a televisão, que já mostrava em alguns de seus programas pessoas em sua vida cotidiana, embora não de forma tão intensa. Desse deslocamento do cinema para a televisão, surge o acesso a uma comunicação de massa.

Posteriormente, foi adaptada pela Endemol ${ }^{3}$ a idéia das webcams para um programa de televisão. Idealizou-se uma casa, na qual os concorrentes seriam, em tempo integral, vigiados por câmeras, e estabeleceu-se a regra básica de eles ficariam isolados completamente de toda a realidade e do convívio externo durante um certo período. A experiência definiu-se como um estudo sociológico cuja intenção era observar a conduta espontânea de indivíduos e suas interações em um espaço microssocial. Ainda de acordo com o site http://bb.sapo.pt/:

1. Título original: The Truman Show. País/Ano: EUA - 1998. Direção: Peter Weir. Elenco: Jim Carrey, Ed Harris, Laura Linney, Noah Emmerich, Natascha McElhone, Holland Taylor, Paul Giamatti, Philip Baker Hall, Brian Delate, Peter Krause. Duração: 103 min. Categoria: Drama. Distribuidora VHS: CIC.

Sinopse: Truman Burbank (Jim Carrey) tem a sensação de que está sendo observado. E ele não faz idéia do quanto está certo. Todos os dias, a cada segundo, desde o momento em que nasceu e durante os últimos 30 anos, Truman vem sendo o astro do show de TV mais longo e popular da história: sua própria vida. A cidade perfeita de Seahaven, que ele chama de lar, é, na verdade, um gigantesco estúdio. Os amigos de Truman e sua família são atores. Todos os momentos de sua vida são captados por milhares de câmeras escondidas. Ao perceber toda a farsa, Truman decide que seu único objetivo deve ser escapar de Seahaven. Indicado ao Oscar em três categorias: Melhor Ator Coadjuvante (Ed. Harris), Melhor Diretor (Peter Weir) e Melhor Roteiro Original (Andrew Niccol).

2. Título Original: The Blair Witch. Project País/Ano: EUA - 1999. Direção: Daniel Myrick, Eduardo Sánchez. Elenco: Heather Donahue, Joshua Leonard, Michael C. Williams, Bob Griffin, Jim King, Sandra Sánchez, Ed Swanson, Patricia DeCou. Duração: 87 min. Categoria: Terror Distribuidora VHS: Europa.

Sinopse: Em outubro de 1994, três jovens estudantes de cinema desaparecem numa floresta de Burkittesville, Maryland, onde pretendiam filmar um documentário sobre uma lendária bruxa da região. Um ano depois, as fitas são encontradas, revelando os estranhos acontecimentos que antecederam o desaparecimento dos jovens. Gravado em vídeo, com total ausência de trilha sonora, o filme tentava simular um documentário verídico, apoiando-se numa eficiente campanha de divulgação na Internet, que afirmava que a fita havia sido realmente encontrada nas florestas de Maryland. Prêmio de revelação no Festival de Cannes de 1999.

3. Endemol é uma empresa de telecomunicações atuante em vários países, dentre eles Portugal e México. 
O nome para o programa foi delineado tendo por base um famoso livro de George Orwell, 1984. A obra relata a existência duma sociedade num futuro pouco distante, na qual todos os movimentos são seguidos por câmeras que controlam a vida de todos. Existe um ser, que nunca descobrimos quem é, que controla todas as câmeras e intervém na vida dos habitantes dessa sociedade. Essa personagem é exatamente o Big Brother.

Esse programa estreou na televisão holandesa em 2000. Como esperado, obteve sucesso imediato, sendo prontamente disseminado para outros países Alemanha, Reino Unido, Estados Unidos, Espanha, Portugal, Suíça, Polônia e Brasil - os quais compraram os direitos de transmissão.

Dessa forma, o reality show possibilita a observação direta e previamente selecionada, de pessoas em seu cotidiano por intermédio de câmeras ocultas que mantêm uma observação vigilante de sua intimidade. Convém sublinhar que seus personagens não são mais objetos idealizados, como artistas ou outros profissionais das diversas áreas da comunicação, mas pessoas comuns e anônimas. Esses programas são apresentados como uma das faces dos gadgets, ${ }^{4}$ enquanto objetos de consumo, com alto valor de gozo porém substituíveis e passíveis de ser rapidamente descartados. Seus personagens saltam do anonimato ao estrelato e deste ao esquecimento com extrema rapidez.

Da intimidade do anonimato à visibilidade da telinha, essas pessoas passam a ser objeto do olhar do Outro, numa relação de submetimento mútuo que envolve grande quantidade de sujeitos, os quais assistem a esses programas, mantendose "aprisionados" a eles. Nessa nova forma de voyeurismo, em que há um interesse intenso no que o outro, enquanto indivíduo suposto igual a mim, faz e como o faz, diz e como o diz, vale supor a emergência de novos processos identificatórios em que se busca um saber no outro, estabelecido não mais em sua dimensão simbólica e hierárquica, como um ideal de ego, mas buscado em sua dimensão imaginária, como ego ideal, que se acredita em condições de instituir a si mesmo e de estabelecer seu próprio ideal, sem necessidade de mudança, no fielmente imitado. Na satisfação obtida no espreitar a vida alheia, sentir a mesma emoção da criança que espiava pelo buraco da fechadura, reconhece-se possível nova forma de voyeurismo, tal como em Freud, que define o voyeurismo como uma forma de privilégio que nos habilita a ver o proibido. Para Freud, a tendência de ver o sexo nu do outro é um antigo componente da libido e a pulsão escópica origina-se no pudor do outro diante da curiosidade infantil. No

4. Gadgets (invenção, coisa prática ou engenhosa; insignificância). Ver Dias Batista, Maria do Carmo. A história e o supermercado. Revista Dora - Revista de Psicanálise e Cultura, p. 36. 
voyeurismo, o privilégio de observar sem ser observado comporta a sensação de tomar posse do observado, afirmar-se sobre ele sem a ameaça da rejeição e tornálo cativo. Experiência vivida invertida da construção de um ego ideal, em que o bebê submetido aos cuidados e ao olhar da mãe se localiza como objeto do desejo do outro.

O voyeurismo foi identificado como uma das formas das perversões descritas como anomalias do instinto sexual, nas últimas décadas do século XIX, por autores pré-psicanalíticos (Krafft-Ebing, 1869; Havelock Ellis, 1890-1900), cujo "... mérito foi, entretanto, reconhecer o caráter sexual de algumas perversões para as quais este caráter não era evidente" (Ey, s/d., p. 383). O DSM-IV descreve:

O foco parafílico ${ }^{5}$ do Voyeurismo envolve o ato de observar indivíduos, geralmente estranhos, sem suspeitar que estão sendo observados, que estão nus, a se despirem ou em atividade sexual. O ato de observar ("espiar") serve à finalidade de obter excitação sexual, e geralmente não é tentada qualquer atividade sexual com a pessoa observada (...) Freqüentemente, esses indivíduos fantasiam uma experiência sexual com a pessoa observada, mas isto raramente ocorre na realidade. Em sua forma severa, o ato de espiar constitui a forma exclusiva de atividade sexual (DSM-VI, 1996, p. 547).

Em contrapartida, nessa nova forma de voyeurismo, não se constata, na observação do corpo nu, a expressão e realização direta de desejos sexuais e sim uma necessidade explícita de observar o outro em sua integridade, dando lugar a um prazer despertado pela via do olhar. Necessário sublinhar que aquele que observa não se dá conta de que seu olhar está sendo conduzido pelo Outro (câmera) e que o observado - suposto objeto de seu olhar, sem que possa se dar conta e ter uma real percepção de que está sendo observado - sabe que todo e qualquer comportamento desperta um constante interesse no outro. Cria-se no que observa, a falsa impressão de ser o sujeito de seu olhar e, no observado a falsa impressão de que seus atos são apenas observados, sem maiores conseqüências. Temos então, no pólo do observado, no sujeito enquanto aquele

5. O foco parafílico vem da descrição de transtornos sexuais relacionados a parafilias, como é o caso do voyeurismo. O DSM-IV assim descreve: "As parafilias são caracterizadas por anseios, fantasias ou comportamentos sexuais recorrentes e intensos que envolvem objetos, atividades ou situações incomuns e causam sofrimento clinicamente significativo ou prejuízo no funcionamento social ou ocupacional ou em outras áreas importantes da vida do indivíduo. As Parafilias incluem Exibicionismo, Fetichismo, Voyeurismo e Parafilia Sem Outra Especificação". Spitzer, Robert L. DSM-IV - casos clínicos: complemento didático para o manual diagnóstico e estatístico de transtornos mentais. 
que encontra satisfação em expor-se ao olhar do outro, uma nova forma de exibicionismo. $\mathrm{O}$ exibicionismo identifica-se, na psicopatologia clássica, como uma necessidade incoercível de obter prazer na exposição dos genitais ao olhar do outro. O DSM-IV o descreve como:

O foco parafílico no Exibicionismo envolve a exposição dos próprios genitais a um estranho. Às vezes o indivíduo se masturba durante a exposição (ou enquanto fantasia que se expõe). Se o indivíduo age sob a influência desses anseios, geralmente não existe qualquer tentativa de uma atividade sexual adicional com o estranho (DSM-IV, 1996, p. 541).

Temos, por um lado, a cultura de massa, ${ }^{6}$ a explorar através de seus meios de forte impacto visual - a saber, a televisão, o cinema e a publicidade - nessa pulsão de ver e seu correlativo de ser visto, um de seus maiores trunfos. Por outro lado, na identificação do sujeito a essas representações imaginárias de si mesmo nas telinhas e em seu submetimento ao consumo de massa, temos um processo de destituição do desejo e de negação do real. Ao reafirmar o interesse demonstrado por todos na contemplação direta da vida alheia e a captação imaginária desta pela televisão, principal meio de comunicação atual, reve-se uma real necessidade de se basear no outro a fim de ser aceito e, mais do que isso, ser igual aos outros. Nada melhor do que os shows da vida real para colocar o indivíduo nesse patamar de angústia: viver a vida de outros. Envolvido a ponto de agir, atuar e estabelecer dependência, a fim de efetivar um laço social perverso do tipo voyeurismo/exibicionismo, caracterizado pelo acompanhamento em tempo integral da vida e do sofrimento do outro, abstraindo-se o sujeito do real de sua própria experiência.

\section{Da identificação imaginária à singularidade do sujeito}

Do desamparo estrutural à necessidade de constituição de sua subjetividade, o sujeito localiza-se entre a pulsão e a simbolização, como sujeito desejante. Da ação da mãe, enquanto outro que o situa como objeto de seu desejo, à ação do

6. O percurso em Freud, que estabelece as relações entre a cultura e os mecanismos psíquicos, inaugura-se com seu ensaio antropológico "Totem e tabu" (1912), com a afirmação de que o incesto é anti-social e a morte do pai, condição da cultura; segue-se "O porvir de uma ilusão" (1927), em que aponta a religião como uma formação ilusória, e culmina em "O mal-estar na cultura" (1930), texto no qual aponta a cultura como constituinte do sujeito e confirma a culpa como estruturante no processo civilizatório. 
pai, enquanto Outro intermediador dos destinos da pulsão, surge o sujeito da diferença: o advento de um sujeito singular (identificação), os limites de seu malestar (recalque) e os possíveis novos alvos e objetos da pulsão (sublimação). Em "Estilo e modernidade em psicanálise", Joel Birman aponta que diante do desamparo estrutural do sujeito é necessário que este invente um estilo de existência para dar conta da singularidade de seu desejo.

O que está em pauta é a figuração de um sujeito da diferença que se confronta permanentemente com as formas existentes de subjetivação, em busca da possibilidade de se constituir como singularidade (...) Com efeito, o que se impõe agora na sublimação é a mudança de alvo e de objeto da força pulsional, pois o sujeito da diferença somente advém com a constituição de outros objetos possíveis para a sua emergência na cena do mundo (Birman, 1991, p. 38).

Ora, para que o sujeito advenha como sujeito da diferença, é necessário que se constitua no registro do desejo como efeito dos processos narcísicos que o situam como ego ideal (objeto do desejo do outro) e que se defronte com o nome do pai $^{7}$ que intermedeia a lei da proibição do incesto e a experiência da castração, instaurando, no ideal do ego, sua particular relação com o gozo.

Um dos fenômenos apontados por diversos autores psicanalíticos acerca de processos característicos da pós-modernidade, no mundo ocidental, tem sido descrito como "a queda do nome do pai", em que a lei não mais se origina nos lugares específicos de onde se enunciava, a saber, do discurso iluminista da ciência ou do discurso religioso do ideário cristão. A família e a escola, tradicionalmente campo de transmissão da lei, dividem o seu papel com novas formas da mídia e, em particular, com a disponibilidade diária e contínua da TV e o acesso direto à Internet, que acabam por fornecer recursos básicos na criação de seus filhos, possibilitando uma maior diversidade de lugares emergentes de "novos nomes do pai". Novos lugares que se multiplicam e se fragmentam, anunciando que todas as formas de gozo $^{8}$ estão permitidas, ao mesmo tempo em

7. Nome-do-pai, s.m. (fr: Nom-du-Père). Produto da metáfora paterna que, designando primeiramente o que a religião nos ensinou a evocar, atribui a função paterna ao efeito simbólico de um puro significante e, em um segundo momento, designa aquilo que rege toda a dinâmica subjetiva, ao inscrever o desejo no registro da dívida simbólica. Chemama, Roland. Dicionário de psicanálise: Larousse, p. 148.

8. O gozo, para a psicanálise é, pois, uma noção complexa, que só encontra seu rigor quando situada na intrincação da linguagem com o desejo, "no falasser". O gozo humano está irredutivelmente marcado pela falta, e não pela plenitude, sem que isso dependa unicamente da problemática. Chemama, Roland. Dicionário de psicanálise: Larousse, p. 94. 
que oferecem e determinam em seus objetos descartáveis a promessa de uma felicidade contínua, embora fugaz e passageira. A boa interpretação não advém mais de uma lei específica, criadora de méritos, que se estabelece no sujeito como um ego ideal a ser alcançado determinando-lhe os limites do que é permitido e do que é interditado, mas surge de todos os lugares, anunciando que todo tipo de prazer é permitido, tudo se torna desejado. Na fragmentação dos lugares do nome do pai, na proliferação da oferta de objetos múltiplos, ideais e acessíveis e na promessa de que toda forma de gozo é possível, impõe-se uma ideologia de mercado que cria, na oferta de objetos efêmeros e descartáveis, uma verdadeira necessidade de se possuir o que se deseja imediatamente e a ilusão dessa possibilidade.

Na propagação e aceitação geral desses programas referentes à vida cotidiana de pessoas comuns, percebe-se a emergência de novas formas de referência ao outro, em que se desperta um voyeurismo inato, em que se precisa do outro para a obtenção de prazer, desde que o outro não tenha conhecimento disso. O sujeito se liga a um objeto desconhecido, o qual se mantém alheio à sua real significação, em que o gozo advém da alienação sujeito/objeto, criando uma relação de distanciamento apoiada na pulsão escópica que se sustenta apenas pelo olhar, sem o toque. No pólo do objeto, o que se percebe é o exibicionismo, que se encaixa no oposto do voyeurismo, em que o sujeito necessita ser olhado e admirado, estabelecendo a necessidade narcísica de ser olhado mas não tocado. Nessa supremacia da pulsão escópica como forma de obtenção de gozo, pode-se correlacionar a forma clássica do voyeurismo/exibicionismo com as atuais. Captado no desejo narcísico de observar e ser observado, o sujeito vê seu gozo interceptado pelo Outro, que, identificado ao poder televisivo da imagem e à intermediação de uma tecnologia voltada à comunicação de massa, determina a lei em que se inscreve, na massificação do desejo, a perda da individualidade do gozo e da singularidade do sujeito.

Silva, em seu texto "Psicanálise e futuro", refere-se à peculiar relação estabelecida entre o desejo e a tecnologia no mundo moderno:

A tecnologia procura estabelecer a adaptação pois ela tem como premissa básica a tese de que, se é bom para um, deve ser bom para todos. Ao perceber a sua individualidade - vestindo, comendo, consumindo, utilizando-se dos mesmos produtos e das mesmas marcas, o homem moderno tem o seu desejo confundido com o desejo do outro, de modo alienado. Até mesmo suas fantasias são resultado exclusivo do desejo do Outro. Mas não se trata apenas de universalizar os padrões. Mais grave é que o desejo é tratado como se fosse uma necessidade. Contudo, a satisfação da necessidade não diz respeito à realização do desejo. Esta confusão vem acontecendo com o desenvolvimento da tecnologia que 
procura criar uma espécie particular de imaginário social no qual se passa a falsa sensação de estados de bem-estar e de completude que seriam conseguidos com a satisfação de necessidades (Silva, 1995, p. 10).

Diante desses dois fenômenos - a alienação do sujeito no desejo do outro e o tratamento do desejo como necessidade - e no cenário promovido pelos reality shows, em que o sujeito é levado a viver a vida do outro, presenciando seus hábitos sem que os personagens tenham consciência de quem os está observando, impõem-se novos laços de natureza narcísica em seus dois pólos: como nova forma de voyeurismo e como nova forma de exibicionismo.

No pólo do voyeurismo, o que se diferencia do voyeurismo clássico é o fato de o objeto da pulsão saber que está sendo observado, retirando-se o caráter do proibido como fonte de satisfação. Mantém-se, no entanto, o caráter narcisista do gozo, na pulsão escópica que sustenta o laço e na alienação do sujeito que autoriza o outro à massificação de seu desejo. Sujeito que se identifica ao ego ideal, sustentado pelo outro suposto igual a mim, e que intercepta qualquer movimento em direção à construção de sua própria subjetividade. Essa identificação narcísica impede a constituição de um ideal de ego assegurado pela figura, função e mediação do nome do pai, ideal possível de ser alcançado na direção da construção de um sujeito que se assegura em seu direito à singularidade.

No pólo do exibicionismo, o sujeito sabe que está sendo observado, mas não quantos ou quem o observa. Em contrapartida, exibe sua privacidade abertamente, privando-se de sua intimidade, o que o coloca numa posição de destaque, deslocando os padrões exibicionistas de prazer sexual para o exibicionismo de todos os momentos da vida. Os integrantes precisam se submeter a um confinamento, o que os remete a uma sociedade criada para eles e por eles. Com a perda da possibilidade de laços de reciprocidade, perde-se a vida social.

A televisão é, por excelência, um lugar que favorece a exibição narcísica, ela é uma máquina também narcísica que fabrica narcisos. ${ }^{9}$ Nela, é possível que artistas, intelectuais, jornalistas e mesmo pessoas comuns apareçam apenas para

9. O termo narcisismo é derivado do mito de Narciso, o qual descreve que Narciso, filho do deusrio Cefiso e de uma ninfa, desprezava o amor embora as ninfas o perseguissem, enamoradas dele. Houve uma Eco que se apaixonou de tal maneira pelo belo mancebo, que emagreceu a ponto de só restarem dela os ossos e a voz. Conta que Nêmesis se encarregou de vingar as mulheres desprezadas. Um dia fez com que Narciso contemplasse o reflexo de seu rosto nas águas de uma fonte, onde fora se refrescar. Insensível a tudo mais, ali ficou o moço, extasiado diante da beleza do rosto que via no fundo da água. E assim permaneceu até morrer. No lugar onde morreu brotou uma flor que se chamou Narciso. Guimarães, Ruth. Dicionário da mitologia grega. 
se tornarem conhecidos e notados sem estarem envolvidos num processo de veiculação de informação, educação ou mesmo entretenimento. No momento em que se criam programas cujo compromisso social está esvaziado, o conteúdo e o valor da matéria são julgados apenas pelo seu apelo estético e pela audiência que consegue contabilizar. O sucesso passa a ser alcançado na captação de pulsões anárquicas e perversamente polimorfas que respondem mais a uma falsa estética e cada vez menos à necessidade de valores e reflexões no plano da ética. Estas servem para curtir a ilusão de prazer do gozo sem limites, em vez de criar e localizar novos objetos para o circuito pulsional, o que comprometeria o sujeito com a dimensão ética de sua existência, obrigando-o a pensar, discutir, trabalhar e discernir o que é válido ou não. O sujeito mantém-se refém de pulsões perversamente polimorfas, no sentido freudiano, que o conduzem mais para o sexo que para o amor, mais para a violência que para a paz, mais para a quantidade de estímulos visuais sedutores que pela qualidade de programação.

Envolvido em relações e formas de interação inautênticas, o sujeito capturado nesse laço narcísico, seja em seu pólo voyeurista seja em seu pólo exibicionista, vê-se incapacitado de encontrar a essência das coisas e de si, investe em práticas falsamente revitalizadoras, difundidas pelo próprio sistema televisivo, quer na direção da perfeição do corpo, quer na tentativa do encontrar sentido para sua existência. Assim é que o exagerado apelo de "culto ao corpo" e o falso envolvimento em "crenças esotéricas", compondo em grande parte o quadro comportamental da sociedade moderna de consumo, revelam tanto sua face narcísica quanto a perda de sentido do eu, que, desorientado pelo não saber e pela imposição vinda da ação do poder homogeneizador da mídia, transfere o significado de seu compromisso histórico para os limites da individualidade, em níveis exacerbados, tentando, com isso, apagar os fantasmas de sua falência. Faltando a consciência de si, o que resta ao sujeito ingênuo é a mera condição de figurante, no imenso e disperso elenco da sociedade de massa (Silva, ibid., 1995).

\section{Conclusão}

Uma das principais reflexões da psicanálise contemporânea acerca do malestar da civilização, aqui entendida como ocidental, cristã e pós-moderna, tem se dado em torno da análise do que se identificou como uma certa falência da função paterna. Esse fenômeno, que encontra raízes já no início do século $\mathrm{XX}$, com o que Nietzsche enunciava como Deus está morto, tem sido apontado como causa de uma série de efeitos observáveis na vida cotidiana do final do século XX e início do século XXI. A própria criação da psicanálise é tributária desse 
enfraquecimento do nome do pai, na medida em que as formações sociais características das democracias modernas, cujo modo de sustentação da lei e da autoridade encontra-se distribuído entre uma série de instâncias simbólicas, têm como efeito o sujeito neurótico, que se credita autônomo e responsável e, portanto, culpado pela construção de seu destino.

No entanto, na pós-modernidade, o lugar de onde partem os enunciados do nome do pai não está apenas dividido entre uma série de instâncias simbólicas; encontra-se também fragmentado e multiplicado, resultando no enunciado de que toda e qualquer forma de gozo é possível. Com a ciência a mando do extraordinário avanço da tecnologia, em particular da tecnologia da comunicação, se favorece em muitos aspectos a constituição de novos laços sociais de natureza perversa que aprisionam o sujeito em processos imaginários de natureza narcísica.

$\mathrm{Na}$ ilusão de unidade do corpo promovida pelo narcisismo e dada pelo investimento parental no bebê enquanto ego ideal é que o sujeito constitui-se enquanto objeto do desejo do outro, pelo outro. Enlaçado numa subjetividade dada pelo outro e instituída não no referencial da singularidade e do estilo, o indivíduoespectador se vê excluído do circuito da troca intersubjetiva e imerso em processos narcísicos. Diante dessa modalidade contemporânea do desamparo, e também das possibilidades que se abrem de perversão do laço social, em que aparentemente falta o pai, é freqüente que se invoque a necessidade de figuras fortes de autoridade e de encarnação imaginária da lei. Na impossibilidade de constituir-se sob a insígnia da diferença e da singularidade, dá-se uma homogeneização das subjetividades. O desejo institui-se no desejo sempre insatisfeito e impõe-se o imperioso desejo de desejar, em que o objeto perde sua singularidade imaginária e simbólica. O lugar do objeto está vazio e passível de ser ocupado por todo e qualquer objeto.

Imperiosamente se impõe o grande Outro na forma de uma ideologia de mercado que ameaça calar Eros e silenciar de forma implacável o poder de desconstrução das organizações ilusórias, promovido pela capacidade sublimatória do circuito pulsional. O inconsciente não mais se apresenta como lugar de estranhamento, a convidar o sujeito a defrontar-se com o real, mas se apresenta como um turbilhão de significantes e significações, iguais e comuns a todos.

A psicanálise, na medida em que reconhece o sujeito como sujeito de seu desejo, instaura o subjetivo no referencial da singularidade e particulariza as relações de gozo, representa uma alternativa ética do sujeito em face da homogeneização de seu desejo e da massificação das identidades. A experiência analítica representa assim as condições para a produção do sujeito da diferença, sujeito do desejo e da singularidade. Aposta no potencial sublimatório das pulsões, sempre capaz de se estabelecer em novos circuitos e de defrontar-se com o real. 


\section{Referências}

Birman, Joel. Estilo e modernidade em psicanálise. São Paulo: Ed. 34, 1997. 240 p.

Chemama, Roland. Dicionário de psicanálise: Larousse. Porto Alegre: Artes Médicas, $1995.240 \mathrm{p}$.

Dias B Atista, Maria do Carmo. A história e o supermercado. In: Revista Dora Revista de Psicanálise e Cultura. Ano 1, n. 1, 1998, p. 36.

Ey, Henry; Bernard, P. e Brisset, C. Manual de psiquiatria. 5. ed. Rio de Janeiro: Atheneu, s/d.

Freud, Sigmund (1912). Totem e tabu. In: Edição standard brasileira das obras psicológicas completas de Sigmund Freud. Rio de Janeiro: Imago, 1969-1977. $24 \mathrm{v}$.

(1917). O porvir de uma ilusão. In: Edição standard brasileira das obras psicológicas completas de Sigmund Freud. Rio de Janeiro: Imago, 1969-1977. $24 \mathrm{v}$.

(1930). O mal-estar na civilização. In: Edição standard brasileira das obras psicológicas completas de Sigmund Freud. Rio de Janeiro: Imago, 1969-1977. $24 \mathrm{v}$.

Guimarães, Ruth. Dicionário da mitologia grega. São Paulo: Cultrix, 1983. 318 p.

Nietzsche, Friedrich W. Gaia Ciência. Coleção Pensadores. In: Obras Incompletas. São Paulo: Editora Nova Cultural, 2000, p. 184.

Silva, Antonio Franco Ribeiro da. Psicanálise e contemporaneidade: psicanálise e futuro. Reverso. Minas Gerais, n. 40, p. 7-15.

SPITZER, Robert L. DSM-IV - casos clínicos: complemento didático para o manual diagnóstico e estatístico de transtornos mentais. Porto Alegre: Artes Médicas, 1996. $401 \mathrm{p}$.

\section{Site:}

História do Big Brother. Disponível em: <http://bb.sapo.pt>. Acesso em: 20/9/2003.

\section{Resumos}

De lo moderno a lo pos moderno nuevas formas de establecer relación con el otro advienen; y en este proceso la imagen, en tanto texto, va ocupando su lugar junto al discurso oral o escrito. El presente trabajo busca establecer algunas reflexiones sobre voyeurismo, tal como es abordado por Freud, desde la perspectiva psicoanalítica clásica, como un trazo de singularidad en la construcción de la sexualidad del sujeto, de aquel proveniente del impacto de lo visual en la construcción de la subjetividad del 
hombre en la pos modernidad, que se presenta en la forma de los reality shows (shows de la vida) televisivos de la actualidad. Dar destaque a estos desplazamientos y sus implicaciones con el deseo, nos lleva a establecer las nuevas formas de mal estar en el mundo contemporáneo.

Palabras claves: Voyeurismo, deseo, reality shows, psicoanálisis, pos modernidad

Du moderne au post-moderne apparaissent de nouvelles façons d'établir des relations avec l'autre et avec ce processus, l'image comme texte occupe sa place conjointement avec le discours, parlé ou écrit. Le travail en question vise à établir quelques réflexions autour du voyeurisme, tel que présenté par Freud dans la perspective psychanalytique classique, en tant que trait de singularité dans la construction de la sexualité du sujet, découlant de l'impact du visuel dans la construction de la subjectivité de l'homme dans la post-modernité, que se présente sous la forme des reality shows (expositions de la vie) télévisés actuels. Donner de l'importance à ces déplacements et à leurs implications dans le désir nous amène à établir les nouvelles formes du mal-être dans le monde contemporain.

Mots clés: Voyeurism, desir, reality shows, psychanalyse, post-modernité

From the modern to the postmodern, new ways of establishing relations with others have come to light, and in this process image has taken its place alongside spoken and written discourse. This article presents reflections on voyeurism, as described by Freud from a classical psychoanalytical perspective as a trait of singularity in the shaping of the subject's sexuality, which results from looking in the construction of subjectivity in postmodern men and women, that can be seen in today's television reality shows (shows of life). Giving importance to these changes and their implications to desire lead us to new forms of discontent in the contemporary world

Key words: Voyeurism, desire, reality shows, psychoanalysis, postmodern bad habits

Versão inicial recebida em julho de 2004

Versão revisada recebida em dezembro de 2004 